\title{
INTEGRAÇ̃̃O CURRICULAR NO ENSINO MÉDIO INTEGRADO À EDUCAÇÃO PROFISSIONAL TÉCNICA: A PERCEPÇÃO DOS EDUCANDOS DO CURSO TÉCNICO EM VESTUÁRIO DO IFUL/CaVG
}

\author{
Viviane Aquino Zitzke \\ Patrícia Mendes Calixto \\ Instituto Federal de Educação, Ciência e Tecnologia Sul-rio-grandense \\ DOI: 10.15628/rbept.2018.7474
}

Artigo submetido em jul/2018 e aceito em ago/2018

\begin{abstract}
RESUMO
O artigo apresenta a percepção dos educandos formandos do Curso Técnico em Vestuário, na forma de ensino integrado, do Instituto Federal de Educação, Ciência e Tecnologia Sul-riograndense (IFSUL), campus Pelotas - Visconde da Graça (CaVG), quando arguidos sobre a integração curricular. Os sujeitos da pesquisa foram 8 educandos do curso em estudo. A abordagem metodológica caracteriza-se por uma pesquisa qualitativa, do tipo estudo de caso, e utilizou questionário misto para a coleta das informações junto aos educandos. $\mathrm{O}$ referencial teórico do estudo está embasado em Ramos (2008; 2011), Fazenda (2011) e Machado (2006) e legislação pertinente. Com relação à existência da integração das disciplinas da formação geral com as da formação profissional, os resultados apontaram que a realização de trabalhos desenvolvidos em sala de aula, se mostrou uma metodologia viável para a articulação de conteúdos.
\end{abstract}

Palavras-Chave: Integração Curricular. Ensino Médio Integrado à Educação Profissional Técnica. Educandos. Curso Técnico em Vestuário.

\section{CURRICULUM INTEGRATION IN MIDDLE SCHOOL INTEGRATED TO TECHNICAL PROFESSIONAL EDUCATION: THE PERCEPTION OF STUDENTS EDUCATIONAL TEACHNICAL COURSE IN CLOTHING IN IFUL/CAVG}

\begin{abstract}
The article presents the perception of the graduates of the Technical Course in Clothing, in the form of integrated teaching, of the Federal Institute of Education, Science and Technology Sul-rio-grandense (IFSUL), campus Pelotas - Visconde da Graça (CaVG), when accused of curricular integration. The subjects of the research were 8 students of the course under study. The methodological approach is characterized by a qualitative research, of the case study type, and used a mixed questionnaire to collect the information with the students. The theoretical framework of the study is based on Ramos (2008, 2011), Fazenda (2011) and Machado (2006) and relevant legislation. With regard to the existence of the integration of the general education and professional training subjects, the results showed that the work carried out in the classroom was a viable methodology for the articulation of contents.
\end{abstract}

Keywords: Curricular Integration. Integrated Higher Education to Professional Technical Education. Students. Technical Course in Clothing. 


\section{INTRODUÇÃO}

O Instituto Federal de Educação, Ciência e Tecnologia Sul-riograndense (IFSUL), campus Pelotas - Visconde da Graça (CaVG), situado na cidade de Pelotas/RS, é o mais antigo campus da instituição. Fundado em 1923, com o propósito de acolher os menores desvalidos, guarda uma história voltada para a educação profissional.

Atualmente, o CaVG oferta educação profissional nos níveis técnico, tecnológico, licenciatura, especialização e mestrado, nas modalidades presencial e a distância. Dentre os cursos técnicos, na forma integrada, encontra-se o técnico em Vestuário, em Meio Ambiente, em Alimentos e em Agropecuária.

O Ensino Médio Integrado à Educação Profissional Técnica (EMIEPT) ${ }^{1}$ é uma forma de ensino que difere de outras escolas, uma vez que propõe a educação voltada para o trabalho, propondo romper com os limites entre o ensino técnico e propedêutico, articulando no ensino princípios do trabalho, da ciência e da cultura. $O$ arranjo curricular do EMIEPT pressupõe a organização de conteúdos que articulem os conhecimentos de formação geral com os da formação profissional, e vice versa, constituindo um currículo integrado.

Dessa forma, o presente trabalho tem por objetivo apresentar a percepção dos educandos formandos do Curso Técnico em Vestuário do IFSUL/CaVG, forma integrada de ensino, sobre a integração curricular.

\section{REVISÃO BIBLIOGRÁFICA}

Os Institutos Federais de Educação, Ciência e Tecnologia (IFs) foram criados através da Lei no 11.892/2008, e se organizaram a partir de instituições já consolidadas pela sociedade, como os CEFETs, escolas técnicas e agrotécnicas federais e escolas vinculadas às universidades federais, partindo, portanto, de uma estrutura existente e ativa.

Os institutos se diferem das universidades por participarem da formação dos indivíduos desde a educação básica até os cursos de graduação (licenciatura, bacharelado, superior de tecnologia) e pósgraduação (especialização, mestrado e doutorado), além de realizarem pesquisa e extensão.

\footnotetext{
${ }^{1}$ Considerarei, para este trabalho, o termo EMIEPT (Ensino Médio Integrado à Educação Profissional Técnica) para designar a Educação Profissional Técnica de Nível Médio na forma Articulada e Integrada ao Ensino Médio, conforme a Resolução no 6/2012, que trata das Diretrizes Curriculares Nacionais para a Educação Profissional Técnica de Nível Médio (DCNEPTNM).
} 
O Ensino Médio Integrado à Educação Profissional Técnica (EMIEPT), parte de uma proposta que se fundamenta na integração entre trabalho, ciência, tecnologia e cultura, os quais conduzem a uma formação integral, ainda que, historicamente, a presença da dualidade ofusque 0 trabalho integrado.

A oferta da Educação Profissional Técnica de Nível Médio, nos termos das Diretrizes Curriculares Nacionais para a Educação Profissional Técnica de Nível Médio (DCNEPTNM), será desenvolvida de forma articulada ou subsequente, conforme é apresentada na norma:

\begin{abstract}
Art. $7^{\circ}$ A Educação Profissional Técnica de Nível Médio é desenvolvida nas formas articulada e subsequente ao Ensino Médio: I - a articulada, por sua vez, é desenvolvida nas seguintes formas:

a) integrada, ofertada somente a quem já tenha concluído o Ensino Fundamental, com matrícula única na mesma instituição, de modo a conduzir o estudante à habilitação profissional técnica de nível médio ao mesmo tempo em que conclue a última etapa da Educação Básica; b) concomitante, ofertada a quem ingressa no Ensino Médio ou já o esteja cursando, efetuando-se matrículas distintas para cada curso, aproveitando oportunidades educacionais disponíveis, seja em unidades de ensino da mesma instituição ou em distintas instituições de ensino;

c) concomitante na forma, uma vez que é desenvolvida simultaneamente em distintas instituições educacionais, mas integrada no conteúdo, mediante a ação de convênio ou acordo de intercomplementaridade, para a execução de projeto pedagógico unificado;

II - a subsequente, desenvolvida em cursos destinados exclusivamente a quem já tenha concluído o Ensino Médio (BRASIL, CNE/CEB Resolução 6, 2012, p. 3, grifo nosso).
\end{abstract}

O Ensino Médio Integrado à Educação Profissional Técnica (EMIEPT), foco deste estudo, busca relacionar as partes do conhecimento, fracionado em disciplinas à sua totalidade, enquanto ciência; ou seja, que os conceitos tenham relação com os procedimentos que compõem o todo, visando a preparar os educandos como cidadãos, bem como, para o qualificado exercício profissional.

A organização curricular baseia-se na integração dos conteúdos entre as áreas técnica e geral, havendo dessa forma a unificação dos conhecimentos e conferindo sentido de continuidade para os educandos. Essa integração não preconiza a hierarquização das ciências, o somatório de conceitos ou a sobreposição de conhecimentos, mas uma verdadeira integração dos saberes e fazeres, calcada em pressupostos da interdisciplinaridade, na busca da totalidade do conhecimento. 


\subsection{Desafios da integração curricular}

Há desafios importantes a serem vencidos no que se refere à integração curricular. Ainda que seja forte a prática disciplinar, pesquisadores apontam para a possibilidade de romper esta lógica.

Nesse sentido, Ramos (2008, p.3) propõe analisar o conceito de integração sob três sentidos que, segundo a autora, se complementam: "como concepção de formação humana; como forma de relacionar ensino médio e educação profissional; e como relação entre parte e totalidade na proposta curricular".

O primeiro sentido atribuído por Ramos (2008, p.3-4) à integração, é o filosófico, pois diz respeito às dimensões da vida dos sujeitos, relacionado com o trabalho, a ciência e a cultura ${ }^{2}$. A autora considera o trabalho como princípio educativo, por que a partir dele posiciona cada um como sujeitos constituintes de história e fazedores da realidade, portanto agente transformador da sociedade.

Para Ferreira e Garcia (2012, p. 170) "a escola é um dos únicos espaços institucionais dos jovens onde a ciência é o objeto de trabalho". Portanto, a ciência como princípio educativo se faz essencial para o processo de superação do antigo pelo novo e as reflexões advindas dessa ação.

Ainda para as autoras (FERREIRA; GARCIA, 2012, p. 170), a presença da cultura como princípio educativo no currículo escolar deve ser considerada de modo amplo, "como a articulação entre o conjunto de representações e comportamentos e o processo dinâmico de socialização, constituindo o modo de vida de uma população determinada." Reforçando que as interações sociais, através das manifestações culturais, promovem o respeito entre os sujeitos e conferem sentido histórico ao conhecimento.

Conforme Ramos (2008, p.12), o segundo sentido guardaria relação com as formas de integração do ensino médio com a educação profissional implementando a conexão de conhecimentos gerais e específicos, etapa de formação em que a "relação entre ciência e práticas produtivas se evidencia; [...] em que ocorre o planejamento e a necessidade de inserção no mundo do trabalho, no mundo adulto. [...] compromisso com a formação profissional mediada pelo conhecimento".

\footnotetext{
${ }^{2}$ Conceitos abordados no Art. $5^{\circ}$, Inciso VIII, Parágrafos $\S 1^{\circ}, \S^{\circ} 2^{\circ}, 3^{\circ}$ e $\S 4^{\circ}$, p. 2 da CNE/CEB. Resolução no 2, de 30 de janeiro 2012, que define Diretrizes Curriculares Nacionais para o Ensino Médio (DCNEM). Disponível em: $<$ http://portal.mec.gov.br/index.php?option=com_docman\&view=download\&alias=9917rceb002-12-1\&ltemid=30192 >. Acesso: em 27maio 2016. Encontrada, também, discussão a cerca destes princípios em: MOURA, H. D. A organização curricular do ensino médio integrado a partir do eixo estruturante: trabalho, ciência, tecnologia e cultura. Revista LABOR.

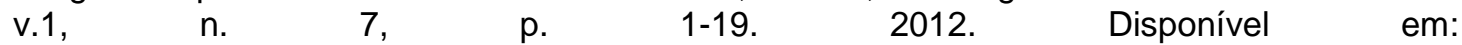
<http://www.revistalabor.ufc.br/Artigo/volume7/1_A_organizacao_curricular_do_ensino_medio integrado_-_trabalho_ciencia_tecnologia_e_cultura_DANTE_LABOR.pdf $>$. Acesso em: 28 out. 2016.
} 
O terceiro sentido dá ênfase na integração entre parte e totalidade na proposta curricular, ou seja, a integração dos conhecimentos gerais e os específicos frente a uma totalidade curricular. Sendo relevante destacar que, nessa perspectiva, "um conhecimento de formação geral só adquire sentido quando reconhecido em sua gênese a partir do real e em seu potencial produtivo" (RAMOS, 2008, p.15).

Portanto, a integração é muito mais que a justaposição de currículos, mas um caminho com objetivos em comum. Considerando o aprimoramento do indivíduo como prioridade, e não a demanda do mercado podemos contribuir com uma pessoa com formação suficientemente reflexiva que possa compreender os mecanismos deste mercado e estar ciente do espaço que ocupa no mundo.

O Documento Base da Educação Profissional Técnica de Nível Médio Integrada ao Ensino Médio, recupera a integração dessa forma de ensino e explica que:

\begin{abstract}
No caso da formação integrada ou do ensino médio integrado ao ensino técnico, o que se quer com a concepção de educação integrada é que a educação geral se torne parte inseparável da educação profissional em todos os campos onde se dá a preparação para o trabalho: seja nos processos produtivos, seja nos processos educativos como a formação inicial, como o ensino técnico, tecnológico ou superior. Significa que buscamos enfocar o trabalho como princípio educativo, no sentido de superar a dicotomia trabalho manual / trabalho intelectual, de incorporar a dimensão intelectual ao trabalho produtivo, de formar trabalhadores capazes de atuar como dirigentes e cidadãos. A idéia de formação integrada sugere superar o ser humano dividido historicamente pela divisão social do trabalho entre a ação de executar e a ação de pensar, dirigir ou planejar (BRASIL, Documento Base, 2007, p.41).
\end{abstract}

Um currículo integrado aponta para a formação integral do educando oferecendo condições de ampliar seu acervo intelectual, propiciando a apropriação de conceitos, capacitando-o para intervir criticamente na sua realidade, tornando-o mais atento as necessidades do meio e responsável pelas suas ações individuais e coletivas.

Dessa feita, Ramos (2011) reitera que "no currículo integrado nenhum conhecimento é só geral, posto que estrutura objetivos de produção; nem somente específico, pois nenhum conceito apropriado produtivamente pode ser formulado ou compreendido desarticuladamente da ciência básica" (RAMOS, 2011, p.776).

Para Sacristán (2013), o desafio da educação, como um todo, é encontrar o equilíbrio entre a educação científica e a educação geral, sem prejuízos para a formação dos educandos, como salienta:

O desafio da educação continua sendo encontrar outras formas de conhecimento escolar, resgatar o sentido da formação geral, revisar a racionalidade baseada na chamada cultura erudita, sem renunciar a ela, mas admitindo a incapacidade da escola para, por si só, levar 
a cabo a modernidade iluminista; algo que se costuma esquecer quando se pedem objetivos contraditórios como preparar para a vida, preparar para as profissões e fomentar a independência de juízo dos cidadãos cultos (SACRISTÁN, 2013, p.33, grifo do autor).

Dessa forma, o processo de ensino e aprendizagem se desenvolve relacionando conceitos peculiares com a totalidade concreta, e vice e versa, interligando a formação geral à formação de profissional. A aprendizagem proporcionada por currículos integrados possibilita maior liberdade na escolha por temas que se vinculem à realidade dos educandos.

De acordo com Machado (2006), a integração das áreas da educação básica e da educação profissional na estruturação do currículo integrado é fundamental para a formação integral do educando, como explica:

\begin{abstract}
A educação básica tem o importante papel de fazer com que o aluno adquira os conhecimentos de base relativos à cultura, à sociedade, às ciências, às idéias, que são indispensáveis a cada um, qualquer que seja sua profissão. [...] Contribui, ainda, para formar para sua autonomia e capacidade para a autoaprendizagem contínua e crítica; para o desenvolvimento da sua criatividade, do seu espírito de inovação e suas disposições à versatilidade que os atuais processos produtivos requerem. [...] A educação profissional tem, nos conhecimentos tecnológicos, seu foco fundamental; conteúdos que não se confundem com saberes empíricos, mas que guardam com eles relação; referências obrigatórias ao exercício de atividades técnicas e de trabalho (MACHADO, 2006, p.55).
\end{abstract}

O currículo, assim idealizado, "é uma relação entre partes e totalidade" (RAMOS, 2011, p.776), pois permite que os educandos vivenciem a integração dos conteúdos, que percebam a reconstituição do conhecimento na ligação entre os conceitos fragmentados nas diversas disciplinas, propostos por este modelo curricular. Entretanto, adverte Fazenda (2011, p.12), que a integração curricular não pode ficar somente na condição de intersecção de conteúdos e métodos, mas no plano da integração de conhecimentos visando uma aprendizagem global.

A fragmentação disciplinar, configurada nas organizações curriculares, não favorece a associação dos saberes, embora bastante desafiadora, começa a ter sua viabilidade apontada em alguns documentos legais. Como é possível identificar no trecho a seguir, extraído da Resolução no 6/2012, da Câmara de Educação Básica do Conselho Nacional de Educação, que define as Diretrizes Curriculares Nacionais para a Educação Profissional Técnica de Nível Médio:

Art. 22-- A organização curricular dos cursos técnicos de nível médio deve considerar os seguintes passos no seu planejamento: [...] V - organização curricular flexível, por disciplinas ou componentes curriculares, projetos, núcleos temáticos ou outros critérios ou formas de organização, desde que compatíveis com os princípios da interdisciplinaridade, da contextualização e da 
integração entre teoria e prática, no processo de ensino e aprendizagem; [...] (BRASIL, Resolução CNB/CEB 6, 2012, p.7).

Trabalhar na perspectiva integradora e interdisciplinar "não é propor a superação de um ensino organizado por disciplinas, mas a criação de condições de ensinar em função das relações dinâmicas entre as diferentes disciplinas, aliando-se aos problemas da sociedade" (FAZENDA, 2011, p.82).

Dessa forma, a integração curricular proposta para o EMIEPT significa um desafio para além da prática disciplinar, pois convoca todos os educadores e educadoras a construir articulações no espaço escolar que visem à formação integral do educando.

Portanto, o êxito da educação profissional integrada ao ensino médio ou EMIEPT, implica na organização de um currículo que supere a dicotomia entre educação básica e técnica, trabalho manual e trabalho especializado, apontando, reciprocamente, para a construção de um documento agregador dos conhecimentos da formação geral aos conhecimentos técnicos, e reciprocamente.

\section{METODOLOGIA}

Esta pesquisa apresenta características qualitativas, do tipo estudo de caso, apesar de fazer uso de aspectos quantitativos para compreender a face qualitativa da educação, pois "toda pesquisa pode ser, ao mesmo tempo, quantitativa e qualitativa" (TRIVIÑOS, 1987, p.118).

Considerando as características de um estudo de caso (YIN, 2010), o primeiro procedimento da pesquisa ${ }^{3}$, foi à análise documental no Projeto Pedagógico de Curso (PPC) do Curso Técnico em Vestuário, verificando se há articulação entre as áreas de formação profissional e de formação geral na matriz curricular.

No seguimento, foi realizada a coleta das informações ${ }^{4}$ com os sujeitos interlocutores da pesquisa, quais sejam educandos formandos do terceiro ano de 2017, do Curso Técnico em Vestuário, na forma de ensino integrado.

Como instrumento para a coleta das informações, foi escolhido um questionário misto, constituído de perguntas fechadas e abertas, aplicado a estes formandos, entendendo que esses já percorreram todas as etapas formativas do curso, e, portanto, são capazes de contribuir com relatos da

\footnotetext{
${ }^{3} \mathrm{O}$ artigo emerge da pesquisa do Mestrado Profissional em Educação e Tecnologia do Instituto Federal de Educação, Ciência e Tecnologia Sul-rio-grandense (IFSUL), no período de 2016 a 2018, registrada no CEP/CONEP sob o número CAAE:70655017.2.0000.8024.

${ }^{4}$ Os procedimentos utilizados para a coleta das informações seguiram as recomendações referentes à ética na pesquisa, conforme a Resolução nº466/12 e a Resolução ํ510/16, ambas expedidas pelo Conselho Nacional de Saúde.
} 
vivência no decorrer da sua formação, tendo como foco as intencionalidades das ações que foram programadas no PPC quanto à integração curricular.

\section{RESULTADOS E DISCUSSOES}

O grupo pesquisado foi composto por oito educandas, do gênero feminino, com idades entre 18 e 20 anos, formandas do ano de 2017 do Curso Técnico em Vestuário, na forma integrada de ensino.

A Tabela 1 corresponde às respostas do questionário, em que foi indagado sobre a presença ou não da integração entre as disciplinas do Curso Técnico em Vestuário e, se afirmativo, em quais as disciplinas e como foi desenvolvida essa prática.

\begin{tabular}{|c|c|}
\hline \multicolumn{2}{|l|}{ Integração Curricular } \\
\hline Disciplinas & $\begin{array}{c}\text { Informações } \\
\text { das } \\
\text { interlocutoras }\end{array}$ \\
\hline Biologia, Português e Desenho de Moda & 08 \\
\hline Ed. Física, Desenho de Moda e Tecnologia Têxtil & 08 \\
\hline História, História da Moda e Desenho de Moda & 07 \\
\hline Física, Desenho de Moda e Tecnologia Têxtil & 06 \\
\hline Química e Conservação dos Artigos do Vestuário & 02 \\
\hline Projeto de Confecção, Tecnologia do Vestuário e Modelagem & 02 \\
\hline Geografia e História da Moda & 01 \\
\hline Sociologia e Gerenciamento de Confecção & 01 \\
\hline Matemática e Desenho de Moda & 01 \\
\hline Tecnologia do Vestuário, Planejamento de Risco e Corte & 01 \\
\hline TOTAL & 37 \\
\hline
\end{tabular}

Fonte: Informações da pesquisa.

Observando a Tabela 1, constata-se que as educandas, interlocutoras desta pesquisa, atribuíram a realização da integração curricular a nove (9) disciplinas da formação geral e nove (9) disciplinas da formação profissional, considerando como um (1) componente as disciplinas ofertadas em mais de um adiantamento, como por exemplo, Física I, Física II e Física II, uma vez que não especificaram as disciplinas.

Por unanimidade, as interlocutoras indicaram a metodologia de trabalhos desenvolvidos em sala de aula, como prática adotada para a realização da articulação dos conteúdos, com destaque para a disciplina de Desenho de Moda, a que mais se envolveu em trabalhos integradores.

Desenho de Moda (DM) é organizado em dois componentes curriculares, DM I e DM II, ofertada no $1^{\circ}$ e $2^{\circ}$ anos, respectivamente. Nesta 
disciplina estudam-se a representação da figura humana feminina e desenhos de peças de vestuário, portanto favorável ao desenvolvimento de trabalhos com os mais diversos temas específicos de cada disciplina, que envolva a aplicabilidade em artigos de vestuário. Como no depoimento desta educanda, que cita as disciplinas que articularam conteúdos e a proposta de trabalho desenvolvido:

\begin{abstract}
Química, comparar os produtos utilizados no mercado do vestuário. Biologia, criar looks inspirados nas plantas e ainda trabalhos sobre o lixo do vestuário. Educação Física, criar roupas para atletas. História, representar as roupas de uma época. Física, criar uma roupa com baixa condução de eletricidade. Português, criar um look. Matemática, tabela com botões. Informática, conhecer os programas utilizados no mercado. Sociologia, criar uma cooperativa na área da moda (Educanda 7)
\end{abstract}

Porém, cabe ressaltar que integração não significa a união de unidades ou conteúdos, mas o entrosamento entre os educadores e educadoras com os conteúdos, conforme destaca Fazenda (2011):

\begin{abstract}
Permanecer apenas na integração de conteúdos, em vez de caminhar para uma mudança ou transformação da própria realidade, pode resultar somente num novo jogo de palavras, numa nova rotulação para velhos problemas, enquanto as causas reais permanecem sem solução, ou mesmo sem questionamento. (FAZENDA, 2011, p. 84)
\end{abstract}

Partilhando desta problemática, percebe-se uma tímida, mas importante, aproximação dos educadores e educadoras na direção da democratização de metodologias, conceitos e teorias das diferentes disciplinas, respeitando as suas características peculiares e singularidades, indo ao encontro da efetiva integração curricular.

Entendo que, essa aproximação e o trabalho colaborativo entre os educadores e as educadoras, estão acontecendo em um processo lento, mas crescente. Porém, são muitas as barreiras a serem transpostas, como indica Fazenda (2011):

A superação das barreiras entre as disciplinas consegue-se no momento em que instituições abandonem seus hábitos cristalizados e partam em busca de novos objetivos e no momento em que as ciências compreendam a limitação de seus aportes. Mais difícil que esta é a eliminação das barreiras entre as pessoas, produto de preconceitos, falta de formação adequada e comodismo. Essa tarefa demandará a superação de obstáculos psicossociológicos, culturais e materiais (FAZENDA, 2011, p. 84)

Encontro apoio nas palavras de Nóvoa (2009, p. 30), quando ele assinala para a necessidade do trabalho colaborativo e coletivo dos educadores e educadoras, em uma "intervenção conjunta nos projectos educativos de escola". Com o trabalho em equipe há a possibilidade de construir passagens, ligando e religando o currículo, como se pode constatar 
nas iniciativas apresentadas na Tabela 1, avançando da direção da integração.

\section{CONSIDERAÇÕES FINAIS}

O Ensino Médio Integrado à Educação Profissional Técnica (EMIEPT) se configura por um currículo que articula conteúdos da formação geral com conteúdos da formação profissional e vice-versa, orientando, portanto, para a efetiva integração curricular.

Nesse sentido, a pesquisa procurou conhecer e analisar o processo de integração curricular no Curso Técnico em Vestuário do IFSUL/CaVG, sob a ótica dos educandos.

Com relação à existência da integração das disciplinas da formação geral com as da formação profissional, pode-se concluir que a realização de trabalhos desenvolvidos em sala de aula, se mostrou como uma metodologia potente e viável para a articulação de conteúdos, atendendo os princípios da integração curricular.

Porém, a integração ainda é um mote a ser perseguido por todos educadores e educadoras do EMIEPT. Apesar dos dez anos da institucionalização dos Institutos Federais, a compreensão do EMIEPT permanece ofuscada pela história dual da educação profissional. Este deve ser um novo capítulo que educadores e educadoras da educação profissional terão que reinventar.

\section{REFERÊNCIAS}

ANTUNEZ, José Leonel da Luz. CAVG: história de um patronato. Pelotas: Ed. Universitária/UFPEL, 1996.

CaVG - uma escola: olhar de aluno. Pelotas: IFSUL, 2016.

ARAUJO, Ronaldo Marcos de Lima. Práticas pedagógicas e ensino integrado. In: 36a Reunião Anual da ANPED - Sistema Nacional de Educação e Participação Popular: desafios para as políticas educacionais. Goiânia/GO, 2013.

BRASIL. Decreto no 2.208, de 17 de abril de 1997. Regulamenta o $\S 2^{\circ}$ do art. 36 e os arts. 39 a 42 da Lei no 9.394, de 20 de dezembro de 1996, que estabelece as diretrizes e bases da educação nacional. Revogado pelo Decreto $\mathrm{n}^{\circ}$ 5.154, de 2004. Disponível em: 
<http://www.planalto.gov.br/ccivil_03/decreto/D2208.htm>. Acesso em 18 jul. 2016.

. Decreto no 5.154 de 23 de julho de 2004. Regulamenta $\circ \S 2^{\circ}$ do art. 36 e os arts. 39 a 41 da Lei n. 9.394, de 20 de dezembro de 1996, que estabelece as diretrizes e bases da educação nacional, e dá outras providências. Disponível em: <http://www.planalto.gov.br/ccivil_03/_ato20042006/2004/decreto/d5154.htm>. Acesso em: 1 jun. 2016.

Lei $\mathrm{n}$ - 9.394, de 20 de dezembro de 1996. Estabelece as diretrizes e bases da educação nacional.

Disponível em: <http://www.planalto.gov.br/ccivil_03/leis/L9394.htm>. Acesso em: 31 maio 2016.

Lei $n$ n 11.741, de 16 de julho de 2008. Altera dispositivos da Lei $n$. 9.394, de 20 de dezembro de 1996, que estabelece as diretrizes e bases da educação nacional, para redimensionar, institucionalizar e integrar as ações da educação profissional técnica de nível médio, da educação de jovens e adultos e da educação profissional e tecnológica. Disponível em: $<$ http://www.planalto.gov.br/ccivil_03/_Ato2007-

2010/2008/Lei/L11741.htm\#art2>. Acesso em: 31 maio 2016.

Lei no 11.892 de 29 de dezembro de 2008. Institui a Rede Federal de Educação Profissional, Científica e Tecnológica, cria os Institutos Federais de Educação, Ciência e Tecnologia, e dá outras providências. Brasília, 2008. Disponível em:<http://www.planalto.gov.br/ccivil_03/_ato20072010/2008/lei/l11892.htm>. Acesso em: 30 jun. 2016.

. Lei $\mathrm{n}$ - 13.415, de 16 de fevereiro de 2017. Altera as Leis $\mathrm{n}^{\text {os }} \mathbf{9 . 3 9 4}$, de 20 de dezembro de 1996, que estabelece as diretrizes e bases da educação nacional, e 11.494, de 20 de junho 2007, que regulamenta o Fundo de Manutenção e Desenvolvimento da Educação Básica e de Valorização dos Profissionais da Educação, a Consolidação das Leis do Trabalho - CLT, aprovada pelo Decreto-Lei no 5.452, de 1 de maio de 1943, e o Decreto-Lei no 236, de 28 de fevereiro de 1967; revoga a Lei $n^{0} 11.161$, de 5 de agosto de 2005; e institui a Política de Fomento à Implementação de Escolas de Ensino Médio em Tempo Integral. Disponível em: <http://www.planalto.gov.br/ccivil_03/_Ato2015-2018/2017/Lei/L13415.htm>. Acesso em: 6 mar. 2017.

MEC. CNE. CEB. Resolução no 2, de 30 de janeiro 2012. Define Diretrizes Curriculares Nacionais para o Ensino Médio (DCNEM). Disponível em:

<http://portal.mec.gov.br/index.php?option=com_docman\&view=download\&ali as=9917-rceb002-12-1\&Itemid=30192 >. Acesso: em 27 maio 2016.

MEC. CNE. CEB. Resolução n 6, de 20 de setembro de 2012. Define Diretrizes Curriculares Nacionais para a Educação Profissional Técnica de Nível Médio (DCNEPTNM). Disponível em: 
<http://portal.mec.gov.br/index.php?option=com_docman\&view=download\&ali as $=11663$-rceb006-12-pdf\&category_slug=setembro-2012pdf\&ltemid=30192>. Acesso em: 27 maio 2016.

MEC. SETEC. Educação profissional técnica de nível médio integrada ao ensino médio - documento base. 2007. Disponível em: $<$ http://portal.mec.gov.br/setec/arquivos/pdf/documento_base.pdf>. Acesso em 9 ago. 2016.

MEC. SETEC. Um novo modelo em educação profissional e tecnológica: concepções e diretrizes. 2010. Disponível em: <http://portal.mec.gov.br/index.php?option=com_docman\&view=download\&ali as=6691-if-concepcaoediretrizes\&category_slug=setembro-2010pdf\&ltemid=30192>. Acesso em: 12 jul. 2016.

MEC. SETEC. Revista Brasileira da Educação Profissional e Tecnológica. v. 2, n. 2, nov. 2009. Brasília. Disponível em: <http://portal.mec.gov.br/index.php?option=com_docman\&view=download\&ali as $=4151$-revista-mec\&ltemid=30192>. Acesso em: 22 ago. 2016.

MEC. SETEC. Revista Brasileira da Educação Profissional e Tecnológica. v. 1, n. 1, jun. 2008. Brasília. Disponível em: <http://portal.mec.gov.br/setec/arquivos/pdf3/rev_brasileira.pdf>. Acesso em: 17 ago. 2016.

. MS. CNS. Resolução 466, de 12 de dezembro de 2012. Aprovar as diretrizes e normas regulamentadoras de pesquisas envolvendo seres humanos. Disponível em: <http://conselho.saude.gov.br/resolucoes/2012/reso466.pdf>. Acesso em: 4 nov. 2017.

MS. CNS. Resolução 510, de 7 de abril de 2016. Dispõe sobre as normas aplicáveis a pesquisas em Ciências Humanas e Sociais cujos procedimentos metodológicos envolvam a utilização de dados diretamente obtidos com os participantes ou de informações identificáveis ou que possam acarretar riscos maiores do que os existentes na vida cotidiana, na forma definida nesta Resolução. Disponível em: <http://conselho.saude.gov.br/resolucoes/2016/Reso510.pdf>. Acesso em: 4 nov. 2017.

CIAVATTA, Maria; RAMOS, Marise. Ensino médio e educação profissional no Brasil: dualidade e fragmentação. Revista Retratos da Escola, Brasília, v. 5, n. 8 , p. 27-41, jan./jun. 2011. Disponível em: <www.esforce.org.br/index.php/semestral/article/download/45/42>. Acesso em: 16 jan. 2017.

FAZENDA, Ivani Catarina A.(Org.). Integração e interdisciplinaridade no ensino brasileiro: efetividade ou ideologia. 6 ed. São Paulo: Loyola, 2011. Disponível

em: 
<http://www.pucsp.br/gepi/downloads/PDF_LIVROS_INTEGRANTES_GEPI/li vro_integracao_interdisciplinaridade.pdf>. Acesso em: 30 maio 2016.

FERREIRA, Eliza Bartolozzi; GARCIA, Sandra R. de Oliveira. O ensino médio integrado à educação profissional: um projeto em construção nos estado do Espírito Santo e do Paraná. In: FRIGOTTO, G.; CIAVATTA, M.; RAMOS, M.(Orgs.). Ensino Médio Integrado: concepções e contradições. 3 ed. São Paulo: Cortez, 2012, p. 149-174.

FRIGOTTO, G. A relação da Educação Profissional e tecnológica com a universalização da Educação Básica. Educação \& Sociedade. Campinas, v. 28, n. 100 (Especial), p. 1129-1152, out. 2007. Disponível em: <http://www.scielo.br/pdf/es/v28n100/a2328100.pdf>. Acesso em: 30 abr. 2016.

FRIGOTTO, G.; CIAVATTA, M.; RAMOS, M.(Orgs.). Ensino Médio Integrado: concepções e contradições. 3 ed. São Paulo: Cortez, 2012.

MACHADO, Lucília. Ensino Médio e Ensino Técnico com currículos integrados: proposta de ação didática para uma relação não fantasiosa. In: BRASIL. MEC. Ensino Médio Integrado à Educação Profissional. Rio de Janeiro, boletim 7, p. 51-68, maio-jun. 2006. Ministério da Educação. Secretaria da Educação a Distância. TVEscola, Salto para o Futuro. Disponível em: $<$ http://portal.mec.gov.br/setec/arquivos/pdf2/boletim_salto07.pdf>. Acesso em: 6 jul. 2016.

MOURA, Henrique Dante. A organização curricular do ensino médio integrado a partir do eixo estruturante: trabalho, ciência, tecnologia e cultura. Revista LABOR. v.1, n. 7, p. 1-19. 2012. Disponível em: $<$ http://www.revistalabor.ufc.br/Artigo/volume7/1_A_organizacao_curricular_d o_ensino_medio_integrado_-

trabalho_ciencia_tecnologia_e_cultura_DANTE_LABOR.pdf $>$. Acesso em: 28 out. 2016.

Fundamentos e Diretrizes Curriculares para o Ensino Médio Integrado no Brasil e no Paraná. Entrevista [2010]. Entrevistador: Suyanne Tolentino. Curitiba, 2010, 3a parte, 14:16min. Entrevista concedida à TV Paulo Freire. Programa Nós da Educação. Publicado em 7 de ago de 2014. Disponível em: <https://www.youtube.com/watch?v=jUEnYSoyQcE\&t=3s\&pbjreload=10>. Acesso em 26 nov. 2017.

NÓVOA, António. Professores imagens do futuro presente. Lisboa: EDUCA. 2009.2 Disponível em:

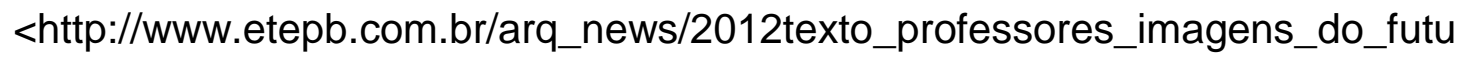
ro_presente.pdf $>$. Acesso em: 10 jan. 2017.

PACHECO, Eliezer (Org.). Institutos Federais: uma revolução na educação profissional e tecnológica. Brasília/ São Paulo: Santillana/Moderna, 2011. 
Disponível

em:

<http://www.moderna.com.br/lumis/portal/file/fileDownload.jsp?fileld=8A7A83 CB34572A4A01345BC3D5404120>. Acesso em: 07 maio 2016.

RAMOS, Marise. Possibilidades e desafios na organização do currículo integrado. In: FRIGOTTO, G.; CIAVATTA, M.; RAMOS, M.(Orgs.). Ensino Médio Integrado: concepções e contradições. 3 ed. São Paulo: Cortez, 2012, p. 107-128.

O currículo para o ensino médio em suas diferentes modalidades: concepções, propostas e problemas. Educação e Sociedade. Campinas, v. 32 , n. 116, p. 771-788, jul.- set. 2011. Disponível em: <http://www.scielo.br/pdf/es/v32n116/a09v32n116.pdf>. Acesso em: 30 maio 2016.

Concepção do ensino médio integrado. 2008. Disponível em: <http://forumeja.org.br/go/sites/forumeja.org.br.go/files/concepcao_do_ensino medio_integrado5.pdf>. Acesso em: 16 abr. 2016.

REGATTIERI, Marilza; CASTRO, Jane Margareth (Orgs.). Ensino médio e educação profissional: desafios da integração. 2. ed. Brasília: UNESCO, 2010.

<http://unesdoc.unesco.org/images/0019/001923/192356por.pdf>. Acesso em: 17 ago. 2016.

SACRISTÁN, José Gimeno (org.). Saberes e incertezas sobre o currículo. Porto Alegre: Penso, 2013.

TRIVIÑOS, Augusto N. S. Introdução à pesquisa em ciências sociais: a pesquisa qualitativa em educação. São Paulo: Atlas, 1987.

YIN, Robert K. Estudo de Caso: planejamento e métodos. 4 ed. Porto Alegre: Bookman, 2010. 